Jussara BIAGINI; Fabiana S. DIAS; Kamila V. MARTINS

\title{
O PROJETO CURRICULAR DE UMA INSTITUIÇÃO DE EDUCAÇÃO PROFISSIONAL TÉCNICA DE NÍVEL MÉDIO NA PERSPECTIVA DO ALUNO \\ THE CURRICULUM OF A HIGH-SCHOOL LEVEL INSTITUTION OF TECHNICAL EDUCATION IN THE STUDENTS' PERSPECTIVE
}

\author{
Jussara BIAGINI* \\ Fabiana Sabará DIAS** \\ Kamilla Veronezi MARTINS ${ }^{* * *}$
}

\begin{abstract}
Resumo: O objetivo deste estudo é analisar as percepções de um grupo de alunos a respeito do projeto curricular de uma Instituição de Educação Profissional Técnica de Nível Médio. As análises se baseiam nas informações e nos dados extraídos do "Questionário Individual de Avaliação Institucional/Concomitância Externa" respondidos pelos alunos, nos anos 2005-2006. Destaca-se que os sujeitos envolvidos no processo investigativo cursaram somente a profissionalização técnica de nível médio na Instituição. Esses sujeitos são portadores de diploma de técnico de nível médio em uma Instituição pública de qualidade. No desenvolvimento do estudo do documento em apreço, se expressa a condição fundamental dos alunos pesquisados em dispor de recursos pessoais e escolares para desenvolver dois currículos diferentes em duas escolas distintas: uma envolve o técnico e a outra se relaciona ao ensino médio. A partir dos dados levantados verifica-se que o lugar ocupado por esses alunos no processo curricular da Instituição se expressa direta ou indiretamente sob a forma do êxito escolar. Observa-se graus de identificação
\end{abstract}

\footnotetext{
Doutora em Educação: História, Política, Sociedade: Educação e Ciências Sociais pela Pontifícia Universidade Católica de São Paulo. Assessora pedagógica da Diretoria de Educação Profissional e Tecnológica do CEFET-MG. E-mail: jubiagini@adm.cefetmg.br

** Mestranda em Educação pela Universidade Federal de Minas Gerais. E-mail: fabianadias@ click21.com.br

${ }^{* * *}$ Graduada em Pedagogia pela Universidade do Estado de Minas Gerais. E-mail: kveronezi@ gmail.com
} 
O projeto curricular de uma instituição de educação...

entre capital escolar apreendido-transmitido pelo grupo de discentes pesquisado e categoria cultural dominante da escola, na condição de assegurar certa correspondência com o modo de produção industrial-urbano. $O$ enfrentamento da tensão entre os princípios continuidade e terminalidade da trajetória escolar traz à tona a questão do destino social do aluno portador do diploma profissional separado do diploma acadêmico.

Palavras-chave: Currículo. Artefato social e cultural. Capital cultural e escolar.

Abstract: The aim of this paper is to analyze the perception and ideas of a group of students regarding to the curriculum of a "High-school Level Institution of Technical Education" ("Instituição de Educação Profissional Técnica de Nível Médio"). The analyses are based on the information and data extracted from the "Individual Questionnaire to Institutional Assessment/External Concomitance" ("Questionário Individual de Avaliação Institucional/Concomitância Externa") answered by the students in 2005-2006. We emphasize that the subjects involved in the survey followed only the high-school level technical education courses at the institution. These subjects have received the diploma of technical level in a public institution of quality. Developing the research of this document, the fundamental condition of the surveyed students is expressed in terms of personal and scholastic resources to apply two different curricula in two distinct schools - one is involved to the technical level and the other is connected to high school. Based on the data obtained, it can be verified that the place occupied by these students in the school's curricular process is expressed directly or indirectly under the form of school success. There are noticeable degrees of identification between school knowledge received and transmitted by the group of students surveyed and the dominant cultural category of the school, to ensure a 
certain correspondence with the urban-industrial type of production. The attitude of facing the tension between the principles of continuity and finalization of the school path brings to surface the question of the social destination of the student who carries a professional diploma separated from the academic one.

Keywords: Curriculum. Social and cultural artifacts. Cultural and school heritage.

\section{INTRODUÇÃO}

O presente estudo concebe o projeto desenvolvido na escola como artefato social e cultural, uma vez que ele implica relação entre saber e poder. Na perspectiva foucaultiana, o conhecimento/saber e o poder estão estreitamente vinculados; nesse particular, entende-se que na escola aprende-se não apenas sobre o que fazer e o que conhecer. Aprender os conteúdos sistematizados no currículo é também aprender disposições, consciência e sensibilidade em relação ao mundo que está sendo descrito. O projeto curricular, elaborado e reelaborado no interior dessa instituição, corporifica noções particulares de "imposição do conhecimento do eu e do mundo que propicia a ordem e a disciplina dos indivíduos" (POPKEWITZ, 1994, p.186).

Considerar o currículo implicado nas relações de poder e nos princípios de controle reforça a idéia da transmissão de visões sociais particulares e interessadas, da (re)produção de identidades individuais e sociais particulares (SILVA; MOREIRA, 2002). Nessa dimensão atenta-se para as condições de dominância de "quem" decide a respeito dos recortes culturais, da visão de mundo, da perspectiva de formação do sujeito que se quer divulgar e que vão nortear as atividades desenvolvidas por professores e alunos que estão espacial e temporalmente situados no processo de escolarização. Ao discutir currículo, há necessidade de apreender seus elementos constitutivos e seus determinantes sociais, buscando compreender, também, limites e possibilidades da formação escolar.

No âmago das reflexões sobre "que tipo de conhecimento vale mais", Apple (1982) investiga "para quem" e "porque" o currículo é direcionado. Sob tais condições, o conhecimento desenvolvido na 
O projeto curricular de uma instituição de educação...

escola passa a ser compreendido como um processo de inculcação de certas culturas, que são concebidas como legítimas. Para Bernstein (1984), as ideologias de educação são ainda ideologias de classes. Pela via de mecanismos de poder e princípios de controle explicitam ou ocultam as formas de hierarquização de determinados conhecimentos e/ou atividades escolares nas quais professores e alunos são interpelados pedagógica e psicologicamente. Dessa forma, tem-se a percepção da escola como organização social. Sob tais circunstâncias, os conceitos "hegemonia", "ideologia" e "tradição seletiva" tornamse fundantes para a apreensão de que os conhecimentos/atividades escolares não são neutros, muito menos as posições dos educadores e educandos, nem mesmos valores materiais e simbólicos resultantes do processo de escolarização.

Ligar a compreensão do projeto curricular a relações de poder e de princípio de controle significa considerar o aspecto contestado desse projeto. A esse respeito reporta-se o conceito de contra-hegemonia, assim explicado por Gramsci (1978, p. 67): "Quanto mais uma classe é autenticamente hegemônica, mais ela deixa às classes adversárias a possibilidade de se organizarem e se constituírem em força autônoma". Com base nessas afirmações, compreende-se que considerar esse aspecto contestado não consiste em negar a existência das relações de poder e de princípios de controle no centro da seleção dos critérios e escolhas curriculares, e sim em evidenciar que tais relações não se realizam conforme os interesses dos grupos ou classes colocados em vantagens no referido centro.

A escola estabelece sua produção em um ambiente no qual, ativamente, se constroem e reproduzem as significações sociais. $O$ processo formativo escolar é considerado zona de produtividade de sentidos e de significados, recebido, produzido e reproduzido a partir do "patrimônio de conhecimento, de competências, de instituições, de valores e de símbolos, constituídos ao longo de gerações e característicos de uma comunidade particular" (FORQUIN, 1993, p. 12), ou seja, é uma zona de cultura. Ressalta-se que essa cultura escolar não resulta em um decalque puro e simples da cultura dominante; muito menos resulta da pressão direta dos interesses de determinado grupo social, o que não descarta a apreensão no interior da escola de um cruzamento de culturas que provocam tensões, aberturas, restrições e contrastes na construção de significados. A especificidade da cultura escolar é destacada, de forma a enfatizar, segundo Furquin 
(1993, p. 19), a "complexidade das relações entre escola e cultura e na impossibilidade de ver naquela o simples veículo ou reflexo de uma cultura posta como uma entidade una e indivisa".

A elaboração de um estudo sobre o projeto curricular desenvolvido pela escola funda-se na percepção do que orienta essa instituição como organização cultural e socializadora em termos reais e concretos, conforme explicita Gimeno Sacristán (1999, p. 17): "O valor da escola se manifesta fundamentalmente pelo que faz ao desenvolver um determinado currículo, independentemente de qualquer retórica e declaração grandiloqüente de finalidades". Esse teórico percebe que o "currículo é um elemento nuclear de referência para analisar o que a escola é de fato como instituição cultural" (p. 18).

É dentro de um quadro teórico no qual o projeto curricular não se refere somente ao processo pedagógico, mas, sobretudo, expressa a relação entre "os processo instrutivos e a realidade da prática a partir de uma perspectiva que lhes dota de conteúdos" (SACRISTÁN, 1999, p.14), que se pretende apreender as percepções dos alunos sobre a proposta de currículo de uma Instituição de Educação Profissional Técnica de Nível Médio . Para tanto, o grupo investigado é formado pelos graduandos dos cursos técnicos na modalidade concomitância externa, nos anos de 2005-2006. As informações e dados descritos e analisados são extraídos do "Questionário Individual de Avaliação Institucional", que foi respondido por esses alunos após realização da atividade curricular "Estágio Supervisionado".

Justifica-se que a tomada do documento em apreço consiste em conceber a possibilidade de descortinar ensaios e/ou entendimentos mais esclarecedores, que são expressos nas opções do aluno da Concomitância Externa quando responde a uma Avaliação Institucional. Esclarece-se que o grupo de alunos investigados é composto por concluintes do ensino técnico, após realização do estágio supervisionado. Esses alunos desenvolvem reflexões estruturadas a respeito da trajetória curricular de profissionalização técnica, em uma Instituição que do ponto vista técnico e acadêmico tem reconhecida a qualidade de seu ensino, o que faz despertar o interesse de jovens de diferentes classes sociais na disputa, a partir de processos seletivos, por uma vaga oferecida por essa Instituição.

A Educação Profissional Técnica de Nível Médio na modalidade Concomitância Externa destina-se a matriculados ou egressos do Ensino Médio, sendo sua estrutura organizativa e curricular própria 
O projeto curricular de uma instituição de educação...

e independente desse ensino. O Decreto 2.208/971 , a Medida Provisória 1.549/97 e a Portaria 646/97 consistem em diretrizes para a separação entre ensino técnico e Ensino Médio, que na Instituição investigada foi implementada a partir do ano de 1999.

No âmbito da escola, tal independência curricular vem se caracterizando pela efetivação da matrícula somente no ensino técnico, sendo o Ensino Médio desenvolvido em uma instituição diferente dessa. Sob tais circunstâncias educativas, explicita-se a condição fundamental em que o aluno precisa dispor de recursos pessoais para desenvolver dois currículos diferentes em duas escolas distintas: uma envolve o ensino técnico e a outra se relaciona ao ensino médio. Logo, o clima escolar manifesta enfrentamento dos limites e possibilidades desse aluno para equilibrar essa situação educativo-formativa, de forma que se estabeleçam as aproximações e as especificidades relativas aos projetos de currículo realizados em duas escolas distintas.

A organização curricular própria, voltada à formação profissional técnica, expõe, preferencialmente, a articulação entre a escola e o mundo do trabalho, de modo a habilitar para o exercício da profissão, de atualizar e aprofundar conhecimento na área técnica, considerando o processo produtivo. Essa prerrogativa ideológica de resgatar a aproximação da escola com o setor produtivo incide, sobremaneira, na possibilidade da inserção de profissionais técnicos necessários ao desenvolvimento eficiente e eficaz de uma enorme gama de atividades produtivas de nível técnico. A oferta da profissionalização técnica concomitante ao Ensino Médio firma-se na perspectiva da formação profissional como desenvolvimento de aptidões para o exercício de uma atividade produtiva, seja esta indicada pelo mercado que determina a escolha profissional, seja pontuada pelo ingresso e melhor desempenho no exercício da profissão como portador de um diploma de técnico de nível médio em uma instituição pública de qualidade.

A fonte de investigação deste estudo estrutura-se nos relatórios dos citados questionários, que foram editados entre os períodos de maio a junho de 2005 , outubro a novembro de 2005 e maio a junho de 2006. Das leituras desses relatórios são extraídos os seguintes dados:

- percentual de alunos por curso;

${ }^{1}$ O Texto legal é revogado pelo Decreto 5154/2004, contudo a oferta dessa modalidade formativa profissionalizante fica garantida no escopo da legislação. 
- adequação da formação tecnológica oferecida pela escola ao exercício profissional;

- coerência entre as disciplinas teóricas e práticas;

- interação entre as disciplinas de educação geral e formação geral;

- interesse em continuar trabalhando como técnico;

- informações quanto ao desejo de prosseguir os estudos.

A apreensão desses dados favoreceu a percepção dos elementos constitutivos referentes à percepção do grupo de alunos investigado quanto à proposta curricular desenvolvida pela Instituição que promove a Educação Profissional Técnica de Nível Médio.

O total de seminaristas, da modalidade concomitância externa, que respondeu ao Questionário Individual de Avaliação Institucional/ Concomitância Externa é de 428, conforme Quadro 1:

Quadro 1 - Total de alunos por curso

\begin{tabular}{c|c|c}
\hline Cursos & Sigla & $\begin{array}{c}\text { Total de questionários } \\
\text { respondidos por curso }\end{array}$ \\
\hline Edificações & EDI & $\mathbf{4 5}$ \\
Eletrônica & ELT & $\mathbf{7 4}$ \\
Eletromecânica & ELM & $\mathbf{1 8}$ \\
Eletrotécnica & ELE & 68 \\
Estradas & EST & $\mathbf{5 6}$ \\
Informática & INF & $\mathbf{2 2}$ \\
Mecânica & MEC & 69 \\
Química & QUI & 46 \\
Equipamentos p/ área de saúde & EAS & $\mathbf{2 5}$ \\
Turismo & TUR & $\mathbf{5}$ \\
\hline
\end{tabular}

Fonte: Departamento de Integração Escola-Empresa da Instituição - DIEE. 2005-2006

Os gráficos a seguir demonstram a postura do grupo de alunos frente à sua formação.

Averigua-se que quase a totalidade de seminaristas acredita que a formação tecnológica da Escola foi adequada ao seu exercício profissional. Destaca-se que esse percentual se torna significativo no Curso de Informática Industrial, à medida que se desconsideram as opções em branco. 


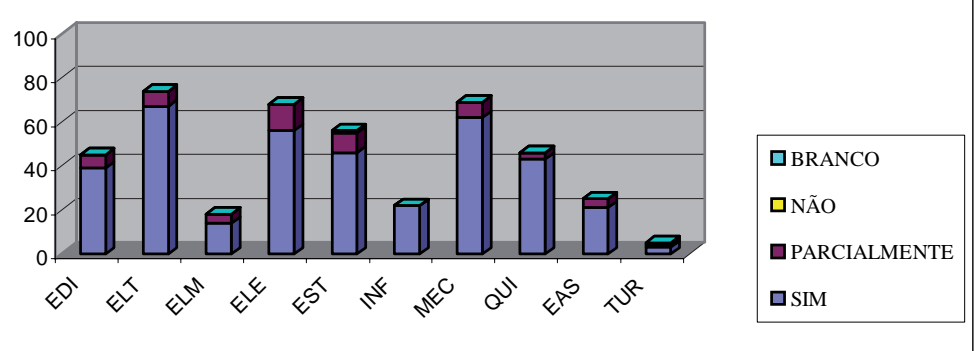

Gráfico 1: Adequação da formação tecnológica da Instituição ao exercício profissional

Fonte: Questionário Individual de Avaliação Institucional/Concomitância Externa - Relatórios do $59^{\circ}, 60^{\circ}$ e $61^{\circ}$

Seminários de Graduação dos Técnicos de Nível Médio da Instituição - DIEE. 2005-2006.

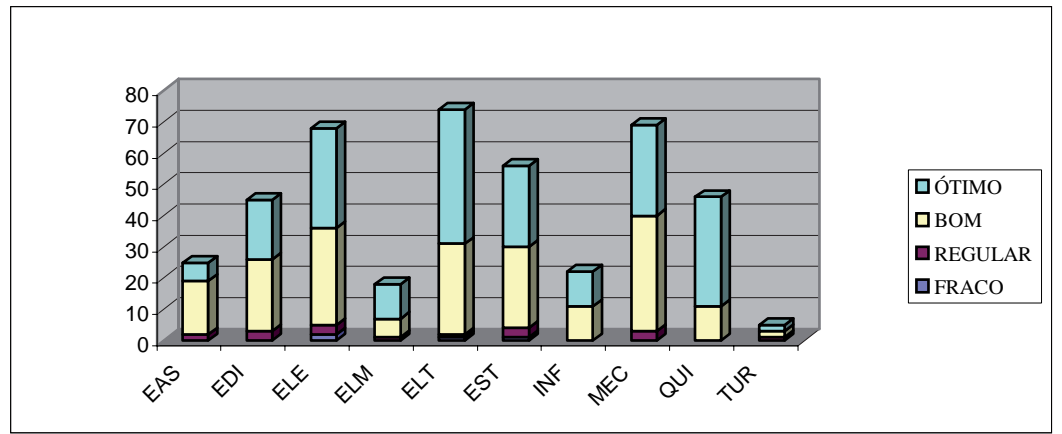

Gráfico 2: Coerência entre as disciplinas teóricas e práticas

Fonte: Questionário Individual de Avaliação Institucional/Concomitância Externa - Relatórios do $59^{\circ}, 60^{\circ}$ e $61^{\circ}$

Seminários de Graduação dos Técnicos de Industriais da Instituição - DIEE. 2005-2006.

Os seminaristas, em sua grande parte, consideram ótima a coerência entre as disciplinas teóricas e práticas. Um maior percentual concentra-se nos cursos de Eletrônica, Química e Eletrotécnica - Automação Industrial. Seguidamente observa-se uma porcentagem expressiva de seminaristas que acreditam que essa coerência entre as disciplinas é boa. Em destaque os cursos de Mecânica, Eletrotécnica - Automação Industrial e Eletrônica.

De acordo com os dados apresentados, observa-se que um grupo considerável de seminaristas compreende que a interação entre as disciplinas de educação geral e formação técnica é boa. Nesses termos, 


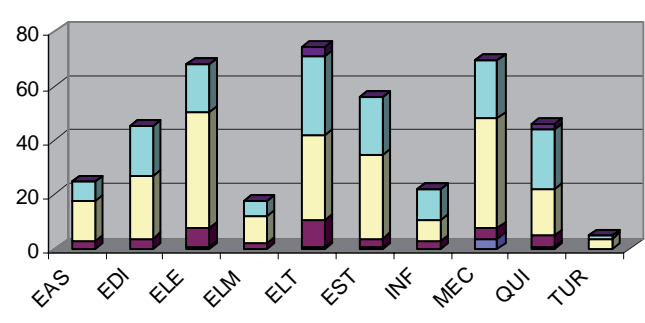

$\square$ BRANCO/NULO

$\square$ ÓTIMO

$\square$ BOM

$\square$ REGULAR

$\square$ FRACO

Gráfico 3: Interação entre as disciplinas de educação geral e formação técnica

Fonte: Questionário Individual de Avaliação Institucional/Concomitância Externa - Relatórios do $59^{\circ}, 60^{\circ}$ e $61^{\circ}$

Seminários de Graduação dos Técnicos de Industriais da Instituição - DIEE. 2005-2006.

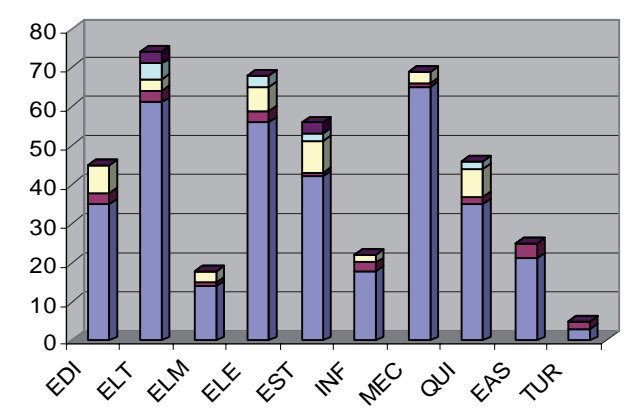

$\square$ NULO

$\square$ NÃO SABE

$\square$ DEPENDE DA OFERTA

$\square \mathrm{NÃO}$

$\square \mathrm{SIM}$

Gráfico 4: Interesse em continuar na área como técnico.

Fonte: Questionário Individual de Avaliação Institucional/Concomitância Externa - Relatórios do $59^{\circ}, 60^{\circ}$ e $61^{\circ}$

Seminários de Graduação dos Técnicos de Industriais da Instituição - DIEE. 2005-2006.

os cursos com uma percentagem significativa são os de Eletrônica, Eletrotécnica - Automação Industrial, Estradas e Mecânica. Há ainda uma frequência expressiva no que tange à concepção de uma ótima integração entre educação geral e formação técnica representada pelos cursos de Eletrônica, Química, Estradas e Mecânica.

É significativo o percentual de alunos que denota interesse em continuar trabalhando como técnico. Percebe-se que a condição de permanecer como técnico deriva da emergência de uma oferta satisfatória do mercado. Destacam-se, ainda, aqueles alunos que não desejam prosseguir na profissão de técnico.

A maioria dos discentes almeja prosseguir na formação escolar, 


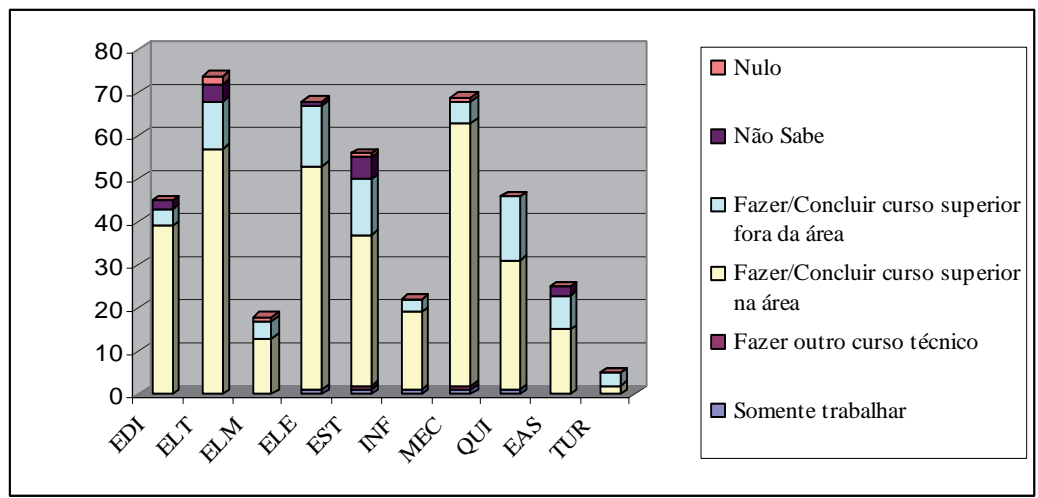

Gráfico 5: Projeto após se graduar como técnico.

Fonte: Questionário Individual de Avaliação Institucional/Concomitância Externa - Relatórios do $59^{\circ}, 60^{\circ}$ e $61^{\circ}$

Seminários de Graduação dos Técnicos de Industriais da Instituição - DIEE. 2005-2006.

após se graduar como técnico, com a intenção de ingressar em um curso superior na área. Posteriormente assinala-se que uma porcentagem representativa tem a pretensão de realizar graduação universitária fora da área técnica.

\section{À GUISA DE CONCLUSÃO}

O currículo escolar não se limita à seleção entre saberes e os elementos culturais disponíveis em dado momento da sociedade; também é tarefa da escola tornar tais saberes e elementos culturais efetivamente transmissíveis e assimiláveis, o que reverte em uma atividade de reorganização e reestruturação do trabalho formativo dessa instituição. Ressalta-se, nessa ótica, o papel da educação na formação da consciência e na relação com outras instâncias. Trata-se de compreender esse papel, buscando ainda identificar a dimensão mais forte dessa formação: se está no campo das agências de controle simbólico ou no campo de agências de produção, na relação com o processo escolar de profissionalização de nível médio, sobretudo no que diz respeito à organização curricular de uma Instituição de Educação Profissional Técnica de Nível Médio.

As reflexões relativas ao "como" do currículo adquirem sentido de importância dentro de uma perspectiva que as considere sob as bases das indagações do "por que" das formas de organização do 
conhecimento escolar. Sob essa ótica, entende-se que o ethos do currículo, em particular do ensino profissional, manifesta-se pela relação entre saber e fazer (teoria e prática) no âmbito escolar, que pode esclarecer o porquê das proposições e a lógica do trabalho escolar como processo que se funda não somente em uma racionalidade técnica, no intuito de obter um certo domínio instrumental-metodológico do "como" fazer esse trabalho escolar, mas também em mecanismos de poder implícitos na hierarquização de determinados conhecimentos escolares.

Constata-se, a partir dos dados levantados anteriormente, que o lugar ocupado por esses alunos no processo curricular da Escola se expressa direta ou indiretamente sob a forma do êxito escolar. A relação sucesso e fracasso assenta-se no "esforço" ou "desafio" desses alunos remanejarem um capital escolar necessário ao acesso e permanência na Instituição. Sabe-se que essa Escola desenvolve um currículo dominante de formação profissional de nível médio construído ao longo de uma trajetória de 97 anos de forma escolar. Sabe-se, também, que existe um consenso quanto à qualidade desse currículo, tanto do ponto vista técnico como acadêmico.

Sob as bases desse currículo, observa-se que o êxito escolar é quase exclusivamente cultural e se funda nos mecanismos de poder e de princípios de controle nos quais se evidencia ou se oculta a percepção de quem define esse currículo. Explicitam-se, nessas condições, os limites e possibilidades de se estabelecer uma apropriação do conhecimento escolar favorável às exigências do currículo dominante dessa Escola.

A natureza do processo formativo dos graduandos da Educação Profissional Técnica de Nível Médio na modalidade Concomitância Externa constitui-se nas condições de remanejar um capital escolar necessário ao atendimento de duas estruturas curriculares independentes: uma que envolve o Ensino Médio realizado em uma outra instituição, e a outra voltada para a profissionalização concluída na Escola pesquisada.

A ilustração abaixo relaciona o número de matrícula efetuada de alunos novatos ingressantes do processo seletivo reservado à Concomitância Externa com o número de alunos graduandos no curso técnico da referida modalidade.

Aponta-se que o número de graduandos nos cursos técnicos na modalidade Concomitância Externa, em comparação com o número 
O projeto curricular de uma instituição de educação...

Quadro 2 - Relação: matrículas efetuadas de alunos novatos X alunos graduandos

\begin{tabular}{c|c|c}
\hline Cursos & $\begin{array}{c}\text { Total de matrículas } \\
\text { efetuadas de alunos } \\
\text { novatos por curso na } \\
\text { concomitância externa } \\
-2005 / 2006\end{array}$ & $\begin{array}{c}\text { Total de alunos gra- } \\
\text { duandos dos cursos } \\
\text { técnicos na modali- } \\
\text { dade concomitância } \\
\text { externa 2005/2006 }\end{array}$ \\
\hline *Edificações & - & 45 \\
Eletrônica & 210 & 74 \\
Eletromecânica & 72 & 18 \\
Eletrotécnica & 120 & 68 \\
Estradas & 160 & 56 \\
*Informática & - & 22 \\
Mecânica & 142 & 69 \\
Química & - & 46 \\
*Euipamentos & - & 25 \\
p/ área de saúde & 35 & 5 \\
**Turismo & 739 & 428 \\
Total & &
\end{tabular}

Fonte: Seção de Registro Escolar da Instituição - SER. 2005-2006 / Departamento de Integração Escola-Empresa da Instituição - DIEE. 2005-2006

* Cursos que deixam de ofertar a modalidade Concomitância Externa em função da implementação do Projeto Curricular da Educação Profissional Técnica Integrada ao Ensino Médio.

* O Curso oferta vagas para processo seletivo de alunos novatos somente no $2^{\text {a }}$ semestre letivo.

de matrículas de alunos novatos efetuadas nesses cursos, entre os anos de 2005 e 2006, certamente, constitui uma evidência da função do currículo dominante da escola, o qual atua seletivamente sobre "aqueles" que possuem um capital escolar necessário para aquisição desse currículo. Não se pretende aqui promover apologia do "déficit", no sentido de considerar os efeitos da determinação do sucesso ou fracasso escolar vinculados a um leque de fatores descritos como consequências da estratificação social. Os estudos de Basil Bernstein mostram que a escola regula suas relações de comunicação, suas exigências, suas avaliações, bem como o posicionamento dos sujeitos (educandos e educadores) em função de seu currículo dominante, ou seja, aquele que tradicionalmente é sedimentado na escola. 
Os cursos técnicos na modalidade Concomitância Externa evidenciam a separação entre certificado "acadêmico" e certificado "profissional". Concebe-se, assim, a perspectiva da educação vocacionalizada, mais relacionada ao campo da produção e mais dirigida pelos princípios desse campo (BERNSTEIN, 1996). Os alunos com entrada somente no curso técnico (sendo o Ensino Médio realizado em outra escola e em outro turno) traduzem as possibilidades de jovens de diferentes classes sociais ingressarem em uma Instituição na qual a boa qualidade do ensino ministrado é considerada por diversos segmentos da sociedade. Embora se examine a seletividade sobre o "quê", o "para quem" e o "por que" da formação profissionalizante, observa-se que os alunos concluintes da Educação Profissional Técnica na referida modalidade consideram que o curso técnico realizado contribui para o seu desenvolvimento pessoal. Tomando de empréstimo as considerações de Costa (1999), o currículo escolar é concebido como lugar privilegiado dos processos de subjetivação, socialização dirigida e controlada. O papel da escola, fundamentalmente da escola de Educação Profissional Técnica, nesse contexto, é colocado em "xeque", uma vez que se atribui a essa instituição a condição de concretizar "um projeto de indivíduo para um projeto de sociedade". (p.51).

A formação tecnológica transmitida/adquirida na escola indica correspondência relativa ao campo da produção, na medida em que se concebe uma base material que se manifesta no terreno transmissão/ aquisição escolar. Essa base material condiz com a particularidade do processo educativo do ensino como resposta a um problema educacional da era tecnológica. O aprimoramento tecnológico que cria novas exigências quanto à qualidade e diversidade de tal formação escolar (SILVA, 1969) e, de certa forma, quanto às necessidades de reformulação do ensino técnico, está condicionado ao progresso tecnológico e às suas consequências sociais. A aceleração da automação e a difusão de novos métodos no setor produtivo têm intensificado mudanças no uso do trabalho e nas características qualitativas da habilidade da mão-de-obra. Mudanças nas qualificações profissionais são exigidas para realização das atividades industriais. A noção de qualificação profissional, no âmbito escolar, constitui-se de uma base científica que condiz com uma formação específica e de base acadêmi$\mathrm{ca}$, de forma que no ambiente escolar o aluno aprenda a relacionar-se com os espaços e os objetos, pela perspectiva da aproximação que 
O projeto curricular de uma instituição de educação...

vivenciará, quando ingressar no mundo do trabalho como técnico de nível médio.

Considerando a especificidade do momento vivido pela sociedade, seja de pleno emprego, seja de subemprego ou de desemprego estrutural, entende-se que a escolha do destino está, fortemente, norteada pela relação diploma-cargo. Essa relação constitui objeto de luta, na medida em que o portador do diploma como força de trabalho tenta valorizá-lo e o detentor do cargo (dos meios produtivos) busca obter essa força de trabalho qualificada pelo menor preço (BOURDIEU, 2002). Na relação de disputa desigual entre detentores dos meios produtivos e portadores de diploma faz-se necessário perceber o poder conferido a certas titulações. O poder do diploma é medido na tensa relação entre capital escolar acumulado e remunerações (material e simbólica) existentes no mercado. A perspectiva de permanecer como técnico de nível médio incide um forte enquadramento na tendência de valorização da educação como estratégia de inserção positiva e criativa no mundo do trabalho, destinada aos jovens entre 18 a 25 anos. Essa faixa etária consiste em referência do grupo de alunos entrevistados. A formação profissional técnica de nível médio no sentido estrito torna-se, portanto, passaporte obrigatório para transmissão/ aquisição de certo volume de conhecimentos, de habilidades e atitudes equivalentes à capacidade de trabalho e de produção.

Entende-se que o projeto curricular elaborado pela Escola, expressando o veio formativo/ideológico da Educação Profissional Técnica concomitante ao Ensino Médio, traz no seu devir limites e possibilidades do trabalho educativo escolar destinado a um grupo específico de alunos. Esses alunos se vêem no processo de escolha entre formação escolar continuada e terminalidade dos estudos. Considera-se que tal escolha é fortemente enquadrada na desigualdade de distribuição de bens materiais e simbólicos entre grupos sociais, que têm uma influência relativamente forte no âmbito escolar. Portanto, põe a nu o destino social desses alunos ao concluírem o Ensino Técnico de Nível Médio na modalidade Concomitância Externa.

$\mathrm{Na}$ visão dos alunos investigados, verifica-se que a estrutura curricular dessa Escola tem seus elementos constitutivos e seus determinantes sociais estabelecidos na definição de que o currículo se desenvolve no grau de identificação entre capital escolar apreendidotransmitido e categoria cultural dominante, na condição de assegurar certa correspondência com o modo de produção industrial-urbano. 
Considerando que há limites nessa pesquisa, as informações e dados singulares, aqui trabalhados, consistem em trazer à tona os posicionamentos e as oposições dos alunos perante o projeto curricular de uma Instituição de Educação Profissional Técnica de Nível Médio na modalidade Concomitância Externa.

\section{REFERÊNCIAS}

APPLE, M. Ideologia e currículo. São Paulo: Brasiliense, 1982.

BERNSTEIN, B. Classes e pedagogia visível e invisível. Cadernos de Pesquisa, São Paulo, n.49, p.26-42, maio 1984.

. A estruturação do discurso pedagógico: classe, código e controle. Petrópolis: Vozes, 1996.

BOURDIEU, P. Escritos de educação. 4. ed. Petrópolis: Vozes, 2002.

BRASIL. Decreto n. 2.208 de 17 de abril de 1997. Regulamenta o $§ 2^{\circ}$ do art. 36 e os artigos 39 a 42 da Lei $n^{\circ}$ 9.394, de 20 de dezembro de 1996 , que estabelece as diretrizes e bases da educação nacional. Diário Oficial da União. Poder Executivo, Brasília, DF, 18 abr. 1997. Disponível em: <http:// www.planalto.gov.br/ccivil_03/decreto/D2208.htm>. Acesso em 28 nov. 2008.

. Decreto n. 5.154 de 23 de julho de 2004. Regulamenta o $\$ 2^{\circ}$ do $\overline{\text { art. } 36}$ e os artigos 39 a 41 da Lei ${ }^{\circ}$ 9.394, de 20 de dezembro de 1996, que estabelece as diretrizes e bases da educação nacional, e dá outras providências. Diário Oficial da União. Poder Executivo, Brasília, DF, 26 jul. 2004. Disponível em: < http://www.planalto.gov.br/ccivil_O3/_Ato20042006/2004/Decreto/D5154.htm>. Acesso em 28 nov. 2008.

. Lei n. 9.394 de 20 de dezembro de 1996. Estabelece as diretrizes e bases da educação nacional. Brasília, 1996. Disponível em: < http://www. planalto.gov.br/ccivil/LEIS/L9394.htm > . Acesso em: 28 nov. 2008.

CEFET-MG. Plano de Desenvolvimento Institucional - PDI: política institucional 2005-2010. Belo Horizonte: CEFET-MG, 2006.

Relatório do $59^{\circ}$ Seminário de Graduação dos técnicos industriais do CEFET-MG. Belo Horizonte: DIEE/CEFET-MG, 2005.

. Relatório do $60^{\circ}$ Seminário de Graduação dos técnicos industriais do CEFET-MG. Belo Horizonte: DIEE/CEFET-MG, 2005.

. Relatório do $61^{\circ}$ Seminário de Graduação dos técnicos industriais do CEFET-MG. Belo Horizonte: DIEE/CEFET-MG, 2006. 
O projeto curricular de uma instituição de educação...

COSTA, M. V. (Org.). O currículo nos limiares do contemporâneo. 2. ed. Rio de Janeiro: DPEA, 1999.

GRAMSCI, A. Concepção dialética da história. 3. ed. Rio de Janeiro: Civilização Brasileira, 1978.

FORQUIN, J.C. Escola e cultura: as bases sociais e epistemológicas do conhecimento escolar. Porto Alegre: ARTMED, 1993.

MOREIRA, A. F.; SILVA, T. T. (Orgs.). Território contestado: o currículo e os novos mapas políticos e culturais. Petrópolis: Vozes, 2002.

POPKEWITZ, T. Histórias do currículo, regulação social e poder. In: SILVAT. O sujeito da educação. Petrópolis: Vozes, 1994.

SACRISTÁN, J. G. O currículo: uma reflexão sobre a prática. Porto Alegre: ARTMED, 1999.

SILVA, G. B. A educação secundária: perspectiva histórica e teórica. São Paulo: Companhia Editorial Nacional, 1969.

Enviado em: 06/07

Aceito em: 02/08 